\title{
Geological nomenclature
}

Sir, - When learning the basic facts of geology the student has to memorize many hundreds of names of rocks, minerals and fossils, and this is made more difficult when the names of many of them have no obvious connection with the things they name. It would seem desirable for names which have no connotation to be modified so as to give a clue to the essential character of the object named.

As an example, I suggest that if the names of the three end-members of the feldspar series of minerals were slightly modified by the addition of one initial capital letter to become $K$ orthoclase, Canorthite and Nalbite, then the essential distinguishing feature would be included in the name by the (international) symbol of the chemical element which each feldspar contains.

25 Valley Crescent,

G. West Wokingham, Berkshire

21 st February, 1970 